\title{
Religião e arte no litoral paranaense: uma releitura das igrejas barrocas do século XVIII
}

\author{
Analine Maquea Cardeal ${ }^{1}$
}

- Enviado em 28/05/2016

- Aprovado em 18/06/2016

\section{RESUMO}

O trabalho analisa a arquitetura campeira a partir da colonização portuguesa e suas influências na construção do centro histórico das vilas fundadas no século XVIII, compreendendo o desenvolvimento da cidade através das construções das igrejas e com isso demonstrar a influência da ocupação portuguesa no uso da arquitetura barroca da época. As construções analisadas são a Igreja de Nossa Senhora do Pilar de 1714, a Igreja do Bom Jesus do Sairá de 1789, ambas de Antonina; a Igreja de São Sebastião do Porto de Cima, de 1779, de Morretes; e a Igreja de Nossa Senhora do Bom Sucesso, de 1766, em Guaratuba.

Palavras-chave: Igrejas, Litoral Paranaense, Barroco campeiro, Brasil Colônia.

\section{INTRODUÇÃO}

O Barroco é um estilo artístico que surgiu predominantemente na segunda metade do século XVI persistindo até o princípio do século XVIII em Roma, porém se espalhou para outros países da Europa, e mais tarde para à América Latina. Foi desenvolvido durante as reformas religiosas que surgiram com o Renascimento, onde a Igreja Católica havia perdido poder e espaço, mas continuava influenciando o cenário político, econômico e cultural na Europa. Na arte a teologia assumiu o controle e impôs restrições às excentricidades maneiristas, buscando reiterar a continuidade da tradição católica, recuperando o decoro na representação, criando uma arte mais acessível para o povo e homogeneizando o estilo. Dessa forma, tudo devia ser submetido de antemão ao gosto dos censores, desde o tema, a forma de tratamento e até mesmo a escolha das cores e dos gestos dos personagens, reintegrando o homem à religião católica (POZENATO, 2013).

\footnotetext{
${ }^{1}$ Graduada em História pela PUCPR. Especialista em História Social da Arte pela PUC-PR. Endereço eletrônico: anamaquea@hotmail.com
} 
A palavra barroco tem um significado que representa totalmente o seu estilo, "pérola irregular" ou deformada, mostrando a ideia de irregularidade. Foi utilizada no campo da arte para expressar a forma com que os artistas não mais observavam as regras rígidas impostas pelo Renascimento. Suas obras são rebuscadas, detalhistas e representam os sentimentos e emoções do ser humano. Na arte barroca europeia predominava a valorização das cores, sombras e a luz, representando o contraste. As imagens fugiam do que era trabalhado nas obras renascentistas, deixando de lado a centralização e optando por uma obra mais dinâmica valorizando o movimento. Seus temas retratavam as passagens da Bíblia, mitologia e história da humanidade. Já as cenas mostravam a vida nobre e seu cotidiano burguês. Os artistas dessa época se dedicavam a decorar as igrejas utilizando a técnica da perspectiva, onde se produzia a ilusão da realidade. As esculturas barrocas mostravam os rostos humanos marcados pela emoção, principalmente o sofrimento. Predominavam as curvas, relevos e a utilização do dourado como cor principal. A fase final do barroco, no século XVIII, é chamada de rococó e possui peculiaridades, como a curva e os detalhes decorativos, assim como à mitologia e os hábitos burgueses (LITTLE, 2010).

O barroco chega ao Brasil pelas mãos dos colonizadores, sobretudo portugueses. Seu desenvolvimento completo se dá no século XVIII, 100 anos após o surgimento do barroco na Europa, estendendo-se até as duas primeiras décadas do século XIX. Como estilo, constitui uma combinação de diversas características barrocas, tanto portuguesas, quanto francesas, italianas e espanholas. O movimento atinge o auge artístico a partir de 1760, transformando-se em uma arte de essência funcional, prestando-se muito bem aos fins a que foi criada: além de sua função meramente decorativa, facilitava a absorção da doutrina católica e dos costumes europeus pelos índios, mas também promovia o cultivo e confirmava a fé e as tradições dos conquistadores cristãos impondolhe sua cultura. Conforme Pozenato,2013, p.13:

No Brasil o movimento foi desenvolvido por um complexo conjunto de influências europeias e adaptações locais, embora em geral destacadas pela interpretação portuguesa do estilo. É preciso lembrar que o contexto em que o Barroco se desenvolveu na colônia era totalmente diferente daquele que lhe dera procedência na Europa. Aqui, no Brasil, ainda estava tudo "por fazer".

Durante o século XVII a Igreja teve um importante papel como mecenas na arte colonial. As diversas ordens religiosas (beneditinos, carmelitas, franciscanos e jesuítas) começaram a se instalar em meados do século XVI no Brasil e desenvolvem uma arquitetura religiosa sóbria e muitas vezes monumental, com fachadas e plantas retilíneas de grande simplicidade ornamental, bem ao gosto maneirista europeu. É somente quando as associações leigas (confrarias, irmandades e 
ordens terceiras) tomam a dianteira no patrocínio da produção artística no século XVIII, momento em que as ordens religiosas veem seu poder enfraquecido, que o barroco se difunde em escolas regionais, sobretudo no Nordeste e Sudeste do país (POZENATO, 2013).

\section{CONTEXTUALIZAÇÃO HISTÓRICA DE ANTONINA, MORRETES E GUARATUBA}

\subsection{ANTONINA}

Os primeiros desbravadores da região de Antonina, situada nos fundos da baía de Paranaguá, eram os faiscadores de ouro. No século XVII, foi concedido pelo Capitão-Povoador da Nova Vila (Paranaguá), Gabriel de Lara, as primeiras três sesmarias de Antonina para os senhores Antônio de Leão, Pedro de Uzeda e Manuel Duarte, dando-lhes a fama de fundadores da região. Somente em 12 de setembro de 1714 o bispo do Rio de Janeiro, D. Frei Francisco de São Jeronimo autorizou a construção da Capela de Nossa Senhora do Pilar da Graciosa, sendo esta data considerada a de fundação da cidade (WACHOWICZ, 2010).

A 29 de agosto de 1797, ocorre a elevação à categoria de Município, com a denominação de Antonina, em homenagem ao príncipe D. Antônio (1795-1802). Filho primogênito do então príncipe regente D. João e D. Carlota Joaquina. Já em 6 de novembro do mesmo ano, foi elevada à categoria de cidade, e somente em 21 de janeiro de 1857, foi transformada em Comarca da Província de São Paulo (WACHOWICZ, 2010).

A construção da Igreja de Nossa Senhora do Pilar remete-se a vontade do capitão-mor Manoel do Valle Porto, o qual, depois de obter autorização do Bispado do Rio de Janeiro para levar a cabo seu plano, dá início às obras utilizando-se dos seus escravos como mão-de-obra. A capelamor foi concluída em 1715 e inaugurada no dia 11 de junho daquele ano. Iniciou-se então a construção do corpo da nave, obra que se prolongou por 18 anos. No dia 17 de agosto de 1733 foi inaugurada a igreja com a celebração de sua benção ${ }^{2}$ (WACHOWICZ, 2010).

\footnotetext{
${ }^{2}$ Ver ANEXO A.
} 


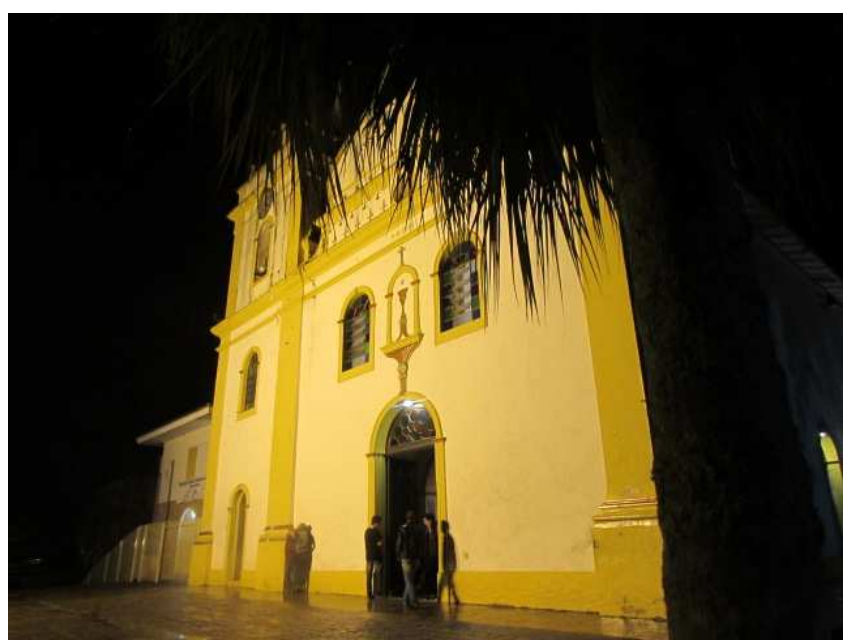

Igreja de Nossa Senhora do Pilar. Arquivo pessoal.

A origem da pequena Igreja do Senhor Bom Jesus do Saivá perde-se no tempo, e segundo tradição oral, D. Serafina Rodrigues Ferreira, esposa do então capitão-mor da vila, Manoel José Alves, vítima de grande enfermidade fizera a promessa de que, caso obtivesse a graça de ser curada, mandaria erguer capela consagrando ao culto do Senhor Bom Jesus. Segundo Ermelino de Leão (1994, p.183) o templo foi construído pela Irmandade de Bom Jesus do Saivá, fundada pelo referido capitão-mor, "e que muito concorreu para sua edificação e que repousa junto à soleira da porta da Igreja, da qual fora protetor". Ao que tudo indica por força do falecimento dos principais patronos, em 1837, a capela não chegou a ser concluída, embora houvesse funcionado regularmente entre 1866 e 1900 quando foi abandonada e, em 1913, fechada, em virtude do desmoronamento parcial da fachada ${ }^{3}$.

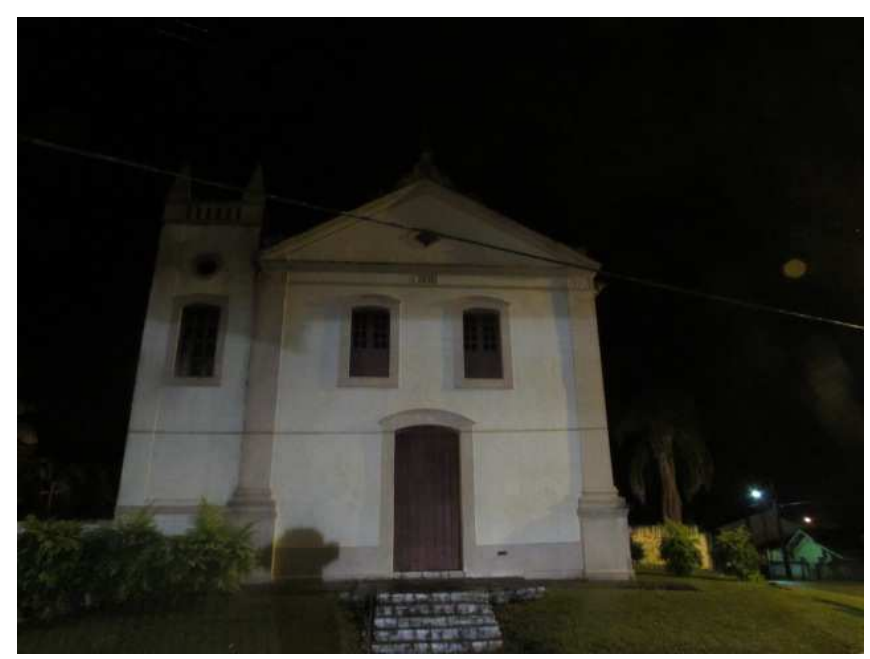

Igreja do Bom Jesus do Saivá. Arquivo pessoal

\footnotetext{
${ }^{3}$ Ver ANEXO B.
} 


\subsection{MORRETES}

Morretes surgiu às margens do rio Nhundiaquara, antes denominado como Cubatão, que deságua na baia de Paranaguá. Nos fins do século XVII e início do século XVIII, era percorrida por aventureiros e faiscadores de ouro. $\mathrm{O}$ rio Cubatão era percurso obrigatório pelos viajantes que, de Curitiba, desciam para o litoral pelo caminho de Itupava. O ouvidor Rafael Pires Pardinho solicitou pelo provimento $n^{\circ}$ 106, à Câmara Municipal de Paranaguá, em 1721, que demarcasse nas margens do rio 300 braças em quadra, para servir de sede a um futuro povoado. Sua preocupação naquela época não era limitada somente a Morretes, estendia-se a Guaratuba, Porto de Cima, Porto do Padre Veiga, Varadouro Velho e rio Sebui (WACHOWICZ, 2010).

Mais tarde, o ouvidor Lanhas Peixoto revogou este provimento do Pardinho. A câmara de Paranaguá apelou à corte em Lisboa, tendo esta novamente confirmada a decisão de Pardinho. E assim em 31 de outubro de 1733, a Câmara de Paranaguá procedeu à medição das 300 braças em quadra no local onde residia João de Almeida, destinando o terreno a futura povoação. O local escolhido era ponto terminal da navegação das canoas para Curitiba (WACHOWICZ, 2010).

No século XVIII, mudou-se para o povoado o Capitão Antônio Rodrigues de Carvalho e sua esposa, Dona Maria Gomes Setubal. Com a chegada do casal, foi construída a primeira capela da região, sob o nome de Nossa Senhora do Porto e Menino Deus dos Três Morretes. Em 1841, passa de vila a Município, pela Lei provincial $\mathrm{n}^{\circ} 16$ de $1^{\circ}$ de março do mesmo ano, com isso acaba sendo desmembrado de Antonina. Trocou de nome em 1869 e passou a se denominar-se Nhundiaquara, porém essa decisão ficou até 1870 quando voltou a ser chamado de Morretes (WACHOWICZ, 2010).

A Igreja de São Sebastião ergue-se em frente à praça principal de Porto de Cima, localidade às margens do Rio Nhundiaquara, a seis quilômetros da sede do município de Morretes. A história de Porto de Cima remonta ao início do século XVIII, com a garimpagem de ouro nos aluviões do Nhundiaquara. Na segunda metade desse século, Porto de Cima ganhou maior expressão devido ao papel desempenhado pelo rio no transporte entre o litoral e o planalto. Em 1779, a fim de dar atendimento religioso à população local, o tenente-coronel D. Afonso Botelho de Sampaio e Souza e o capitão Antonio Rodrigues de Carvalho iniciaram a construção de uma capela sob a invocação de N. Sra. da Guia e de São Sebastião. Na primeira metade do século XIX, a região, devido às facilidades de transporte e de força motriz oferecida pelo rio passou a abrigar 
engenhos hidráulicos de beneficiamento de erva-mate - produto que assumira grande importância no mercado internacional, devido a problemas de ordem política na região platina.

Com o crescimento populacional da localidade, fez-se necessário ampliar a capela, recebendo seus zeladores, na década de 1840, autorização para as devidas obras. A transferência dos engenhos ervateiros para o planalto e a construção da ferrovia ligando-o ao litoral vai esvaziar economicamente Porto de Cima, iniciando-se sua decadência, afetando, inclusive, a reforma da capela, cujas obras se arrastaram por quase meio século ${ }^{4}$.

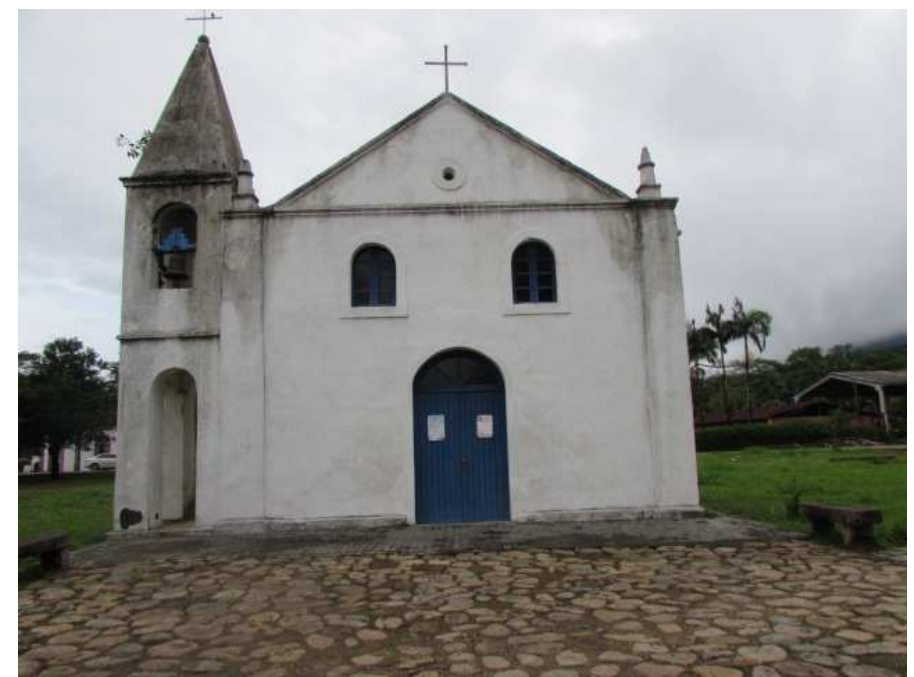

Igreja de São Sebastião do Porto de Cima. Arquivo Pessoal.

\subsection{GUARATUBA}

D. Luiz de Souza Botelho Mourão, Morgado de Mateus, ordenou no dia 5 de dezembro do ano de 1765 a Afonso Botelho de Sam Payo e Souza, que fundasse um povoado em Guaratuba. A fim de executar as ordens, Sam Payo e Souza reuniu em torno de 200 casais para serem transferidos para a região da enseada, dando-lhes terras e aparatos de acordo com a necessidade de cada casal. Em 13 de maio de 1768, Mourão solicitou a construção de uma igreja no novo povoado, e no dia 29 de abril de 1771 foi celebrada a primeira missa, a qual oficializou o Pároco Bento Gonçalves Cordeiro e teve como ajudantes os padres Frei João Santana Flores e Francisco Borges, e nesta mesma data, o povoado se torna vila com o nome de Vila São Luiz de Guaratuba da Marinha.

\footnotetext{
${ }^{4}$ Ver Anexo D.
} 
Pelo decreto estadual $n^{\circ} 7573$, de 20 de outubro de 1938, o Município de Guaratuba é extinto, e começa a fazer parte de Paranaguá como Distrito. Foi restaurado em 10 de outubro de 1947, pela lei ${ }^{\circ} 2$, sendo restituída sua autonomia no dia 25 de outubro de 1947 (BALHANA, 1969).

A Igreja Matriz de Nossa Senhora de Bom Sucesso começou a ser construída no ano de 1768 e recebeu a benção no dia 28 de abril de 1771, do Reverendo Bento Gonçalves Cordeiro, ajudados pelos Padres Frei João de Santana Flores e Francisco Borges, e no dia 29 foi celebrada a primeira missa. Construída pela comunidade e desenhada por Afonso Botelho, é de arquitetura religiosa colonial e apresenta uma fachada bastante simples de alvenaria ${ }^{5}$, como eram as demais igrejas litorâneas da época. Internamente é ornamentada por um retábulo discreto, provavelmente do século passado. Na igreja eram sepultadas as pessoas da comunidade, isto durante 86 anos, até que se construiu o cemitério municipal. Os sepultamentos, dependendo do lugar, tinham um determinado preço: 320 réis, 640 e 1280 réis (perto do altar) ${ }^{6}$ (WACHOWICZ, 2010).

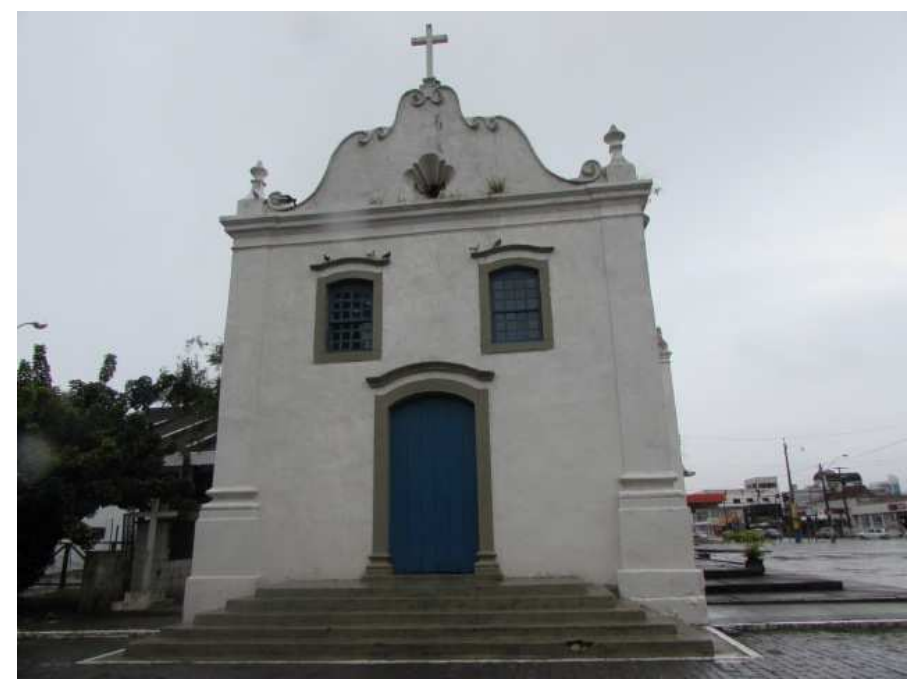

Igreja de Nossa Senhora do Bom Sucesso. Arquivo pessoal.

\footnotetext{
${ }^{5}$ Alvenaria: É a construção de estruturas e de paredes utilizando blocos unidos entre si por argamassa.

${ }^{6}$ Ver Anexo C.
} 


\section{CARACTERIZAÇÃO DA ARQUITETURA BARROCA}

No começo do século XX, enquanto Antonina vivia uma fase de prosperidade econômica decorrente da intensa atividade de exportação de seu porto, a Igreja de Nossa Senhora do Pilar passou por uma completa restauração, iniciada em agosto de 1926 e concluída em fevereiro de 1927. Já em 1952, foi realizada uma segunda grande intervenção, com o objetivo de melhorar as condições de conforto interno, porém, nesta restauração às características originais de sua arquitetura não foram respeitadas. São substituídas as janelas de madeira por esquadrias ${ }^{7}$ de ferro, tipo "vitrô"8, a cobertura é elevada, o assoalho é trocado por piso cerâmico e são eliminadas as pinturas parietais ${ }^{9}$. Outra restauração é feita na década de 1970, chegando a prejudicar o exterior da igreja: a construção de uma edificação para abrigar a casa paroquial e a secretaria da Congregação Redentorista ao lado da Igreja. Preocupada com outras ações que pudessem prejudicar mais ainda o monumento, a Câmara Municipal de Antonina, em 1995, solicitou o tombamento da igreja, alegando especialmente à necessidade de proteger o altar-mor ${ }^{10}$, construído em mármore de Carrara $^{11}$ e instalado em 1930. Situada sobre um morro e inserida de frente para o mar, obtendo uma vista privilegiada de parte da baia do município e das ruinas do antigo Porto, a igreja de Nossa Senhora do Pilar, embora prejudicada pela introdução da Casa Paroquial ao seu lado, guarda presença significativa na paisagem de Antonina. Sua arquitetura externa mantém ainda algumas características da época da sua construção, como a composição volumétrica em quatro blocos: à frente e com maior porte, a nave ${ }^{12}$ e a torre, seguidas dos volumes mais baixos formados pela capela-mor ${ }^{13}$ e sacristia ${ }^{14}$. A torre, situada à esquerda da nave, é coroada por zimbório ${ }^{15}$ em forma de sino. Na fachada da nave, o coroamento é feito por frontão ${ }^{16}$ de desenho sinuoso semelhante ao

\footnotetext{
${ }^{7}$ Esquadrias: Janelas.

8 Vitrô: É uma janela que pode ser de correr ou abrir, e que não possuí veneziana.

9 Parietais: Pintura realizada diretamente na parede, como um afresco.

10 Altar-mor: altar principal de uma igreja, localizado em ponto oposto à porta de entrada.

${ }^{11}$ Mármore de Carrara: tipo de mármore produzido na cidade de Carrara, na Itália.

${ }^{12}$ Nave: Espaço livre no interior das igrejas designado aqueles que assistem aos rituais religiosos. se

${ }^{13}$ Capela-mor: Nas igrejas, capela principal onde fica o altar-mor.

${ }^{14}$ Sacristia: Casa anexa a uma igreja onde são guardados os objetos de culto, e onde os padres tomam as vestes do culto.

15 Zimbório: É o nome dado à parte mais alta e exterior da cúpula, em forma de torre, em geral circular ou octogonal, das igrejas e edifícios de grande dimensão.

${ }^{16}$ Frontão: Elemento de coroamento da fachada em forma triangular, aproximadamente triangular ou em arco de circulo, situado na parte superior ou de parte da edificação ou sobre portais, portadas ou portões.
} 
perfil do zimbório. Entretanto, na composição dos vãos ${ }^{17}$, terminados em arco pleno ${ }^{18}$, e na aplicação de elementos decorativos feitos de massa, percebe-se que houve modificações ao gosto eclético do início do século XX, executadas provavelmente durante a reforma concluída em 1927 (SEEC, 2006).

A Igreja do Bom Jesus do Saivá, bastante arruinada, foi tombada pelo Patrimônio Histórico e Artístico do Estado em 1970, que em seguida cuidou da sua restauração. Ficou fechada para as obras até sua reinauguração em 28 de julho de 1976. Compõe-se de quatro corpos: nave, capelamor, sacristia e torre sineira ${ }^{19}$. Construída em alvenaria de pedra, sobre a fachada enquadrada por cunhais $^{20}$, destaca-se frontão triangular vazado por óculo ${ }^{21}$ e encimado por cruzeiro ${ }^{22}$. Portada emoldurada em cantaria ${ }^{23}$, com verga ${ }^{24}$ e sobreverga ${ }^{25}$ arqueada. À altura do coro, duas janelas de folha cega, emolduradas por requadros em massa, encimados por vergas encurvadas e dois óculos. A nave possui duas portas de acesso lateral. Cobertura em telha capa-e-canal ${ }^{26}$, arrematada por beiral $^{27}$ em cimalha ${ }^{28}$. Em seu interior, bastante simples, destaca-se a imagem do orago ${ }^{29}$, Bom

\footnotetext{
17 Vão: Genericamente, espaço vazio nas paredes e muros ou abertura em paredes correspondente a portas e janelas. Nos Arcos (elemento construtivo curvo usado comumente na ligação entre dois apoios), distância entre pés-direitos (altura que vai do piso ao teto nos compartimentos ou recintos de um edifício).

${ }^{18}$ Arco pleno: Semicircunferência formada a partir de um só centro descrevendo um ângulo de $180^{\circ}$.

${ }^{19}$ Torre-Sineira (Campanário): Pequena torre para colocação de sinos.

${ }^{20}$ Cunhais: Encontro de duas paredes externas, serve de proteção a quina do edifício ou para ornamentação da fachada, construído de material diferente do utilizado na alvenaria das paredes.

${ }^{21}$ Óculo: uma abertura na fachada ou no interior que pode ser redonda ou de outras formas, localizada geralmente acima de uma abertura principal ou inclusa em frontões e frontispícios.
}

${ }^{22}$ Cruzeiro: é o espaço situado na intersecção da nave central com transepto nas igrejas ou catedrais cristãs que apresentam uma planta em forma de cruz romana.

${ }^{23}$ Cantaria: Alvenaria de pedras, talhadas uma a uma, de modo a se ajustarem perfeitamente umas as outras se necessidade de material ligante.

${ }^{24}$ Verga: Peça colocada em um vão de porta ou janela, apoiada sobre as ombreiras em suas extremidades.

${ }^{25}$ Sobreverga: Moldura colocada nas fachadas sobre as vergas de janelas e portas para realçá-las e protegê-las da chuva.

${ }^{26}$ Telha capa-e-canal: Também conhecida como telha colonial, à telha capa e canal é constituída de argila e tem forma côncava, são assentadas em fileiras com posição invertidas.

${ }^{27}$ Beiral: última fileira de telhas que forma a aba do telhado.

${ }^{28}$ Cimalha: Arremate emoldurado formando saliência na superfície de uma parede.

${ }^{29}$ Orago: Segundo o costume católico, Patrono, orago ou padroeiro é um santo ou anjo a quem é dedicada uma localidade, povoado ou templo (capela, igreja etc). 
Jesus do Saivá, restaurada pela professora Maria Ester Teixeira $\mathrm{Cruz}^{30}$. A imagem, que havia sido furtada da igreja, foi recuperada em 1985.

Já em Morretes, a igreja de Porto de Cima mostra em sua arquitetura os dois processos processos históricos que passou, pois na ampliação feita no século XIX a antiga capela passou a ser passou a ser a capela-mor da igreja. Como a primeira igreja era aberta para o lado oposto, sua sua fachada, de principal passou a fundos, fazendo com que a igreja ficasse dotada de dois frontispícios $^{31}$, com isso a comissão encarregada da obra, em 1874, solicitou ao presidente da da província, que fosse autorizada a demolição do corpo da igreja, alegando a falta de proporção e proporção e simetria do conjunto, por sorte a obra não chegou a ser executada. As duas fachadas fachadas são hoje um testemunho da história local. A original correspondendo à fase áurea de Porto de Porto de Cima, é mais rica: o partido tradicional, de frontão triangular, é ornamentado por um por um par de volutas ${ }^{32}$, de desenho típico do século XVIII, sobrepostas ao seu ápice. Pináculos ${ }^{33}$ Pináculos ${ }^{33}$ demarcam os três pontos do ático ${ }^{34}$ e um cordão denticulado borda os lados. $\mathrm{O}$ retângulo dessa fachada é emoldurado por cunhais de seção semicircular. A porta de entrada foi entrada foi entaipada, havendo hoje um único vão nessa fachada - uma janela retangular. Lateralmente, foi construída a sacristia, com o comprimento da antiga capela. Seus vãos de janelas, janelas, em arco pleno, datam da segunda metade do século XIX. A fachada atual, extremamente extremamente simples, compõe-se de um retângulo, vazado por uma porta de verga reta e um par de um par de janelas de arco pleno, coroado por um frontão triangular. Os únicos adornos são os os pináculos laterais, de desenho e feitura rudimentares. Ladeia o frontispício uma pequena torre de torre de vãos em plena volta e zimbório piramidal, que pela desarmonia que apresenta em relação à relação à nova fachada deve ter sido erguida em época mais recente. Internamente, não há elementos artísticos valiosos, tendo sido o edifício vítima de muitas reformas desfigurantes, cujas consequências foram, em parte, atenuadas por trabalhos de restauração realizados após seu tombamento (SEEC, 2006).

\footnotetext{
${ }^{30}$ Maria Ester Teixeira Cruz: do ateliê de restauro do Solar do Barão da Fundação Cultura de Curitiba. IN: Estado do Paraná de 04/11/1986

${ }^{31}$ Frontispício: fachada principal de um edifício; frontaria.

${ }^{32}$ Volutas: Ornamentos em forma de espiral encontrados nos altos das colunas ou em arremates de corrimãos

${ }^{33}$ Pináculo: é o ponto mais alto de um determinado lugar, um edifício ou uma torre, por exemplo. O pináculo é uma alvenaria empregue como peso no cume de um contraforte ou em forma decorativa como remate.
}

34 Ático: último piso do edifício. 
Já a Igreja de Nossa Senhora do Bom Sucesso, em Guaratuba, possui linhas coloniais muito simples, foi edificada em alvenaria de pedra argamassada e atualmente divide-se em quatro corpos: nave, capela-mor, sineira e sacristia. Enquadrada por cunhais, arrematados por coruchéus, ambos em cantaria, a fachada principal é dividida por porta e duas janelas à altura do coro. Todos os requadros da fachada são também em cantaria, vergas e sobrevergas arqueadas. O frontão é movimentado por graciosas curvas e contracurvas e vazado por óculo poli lobulado. Diferentemente dos estilos adotados na região, a torre sineira, obra do século XIX, se fixa recuada, diante da sacristia, à qual dá acesso através de porta emoldurada por requadro em cantaria, com verga e sobreverga arqueadas. A aquarela de Debret, feita em 1827, mostra a matriz ainda sem a atual sineira, o que comprova sua posterior edificação, conforme imagem abaixo. Coroam a fachada principal dois coruchéus em cantaria. A cobertura compõe-se de duas águas, com telhas do tipo capa-e-canal, apresentando beiral em beira-seveira. Nas fachadas laterais há três janelas altas e uma porta central. Toda a cantaria utilizada na edificação foi trazida, já lavrada, da Ilha do Mel. O interior da igreja é bastante simples, com piso de tabuado e a nave, em abóbada de berço, tem forro de tábuas corridas, arrematado por cimalha.

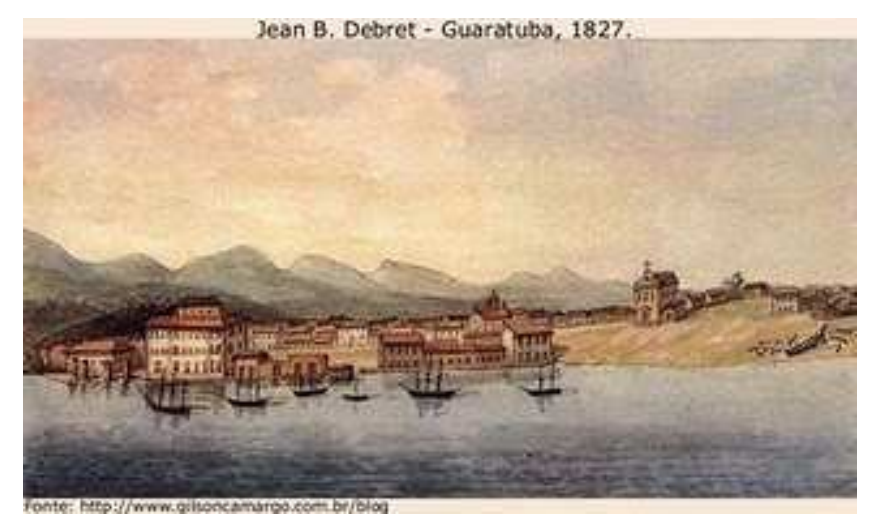

\section{CONSIDERAÇÕES FINAIS}

Para podermos analisar as igrejas barrocas portuguesas pertencentes à região sul do Brasil, primeiramente temos que saber quais as principais características dos monumentos deste estilo arquitetônico, são elas: a tipologia dos edifícios (igreja ou palácio); recursos a linhas e superfícies 
onduladas, a volutas ${ }^{35}$ e orelhões ${ }^{36}$; construções de plantas complexas (uso da forma oval); jogos de luz para efeitos cenográficos; uso de ornamentações abundantes e a criação de uma nova ordem: a ondulante.

Em sua pesquisa intitulada A Arquitetura No Paraná: Uma Contribuição Metodológica Para A História Da Arte, Key Imaguire Junior (1982) ${ }^{37}$ faz um levantamento de todas as obras religiosas realizadas em determinados períodos da história da arquitetura do Paraná. É com a ajuda de sua pesquisa e do material coletado que podemos realizar uma análise das igrejas.

Considerando o material disponível para a análise, podemos perceber que as igrejas sofreram bastantes alterações com as restaurações ocorridas para a sua preservação, estas que em alguns casos, como a Igreja de Porto de Cima, acabaram por danificar a arquitetura original. Outro exemplo é a Igreja de Nossa Senhora do Pilar, que em sua segunda restauração, as características internas não foram respeitadas (trocas de janelas, pisos, etc), e em sua terceira restauração, a parte externa sofre alterações, levando assim ao seu tombamento.

Apesar da dificuldade de encontrar fontes que nos leve a influência certa dos portugueses na arquitetura da época estudada, podemos dar créditos a eles pela divulgação do estilo a partir da sua chegada para o povoamento. Muitas dessas Igrejas têm relação direta com a devoção das famílias pelos Santos, como as igrejas de Antonina e de Morretes.

Percebe-se que algumas igrejas são frutos de famílias portuguesas: a Igreja do Senhor Bom Jesus do Saivá, que foi construída em base numa promessa feita pela família do Capitão- Mor Manoel José Alves, oriundo da freguesia de São Salvador da Fonte Boa em Portugal; a Igreja de Nossa Senhora do Pilar feita por Manoel da Villa Porto, que nasceu em 1670, em Valongo, no distrito do Porto, em Portugal; e a Igreja de São Sebastião do Porto de Cima, onde seu fundador Afonso Botelho de Sampaio e Souza nasceu em Vila Real, Portugal (LYRA,1994).

\footnotetext{
${ }^{36}$ Orelhões: Elementos em forma de fita encurvada e enrolada nas extremidades, que serviam para articular, ou unir dois pontos situados a alturas diferentes.

$37 \quad$ Disponível em http://acervodigital.ufpr.br/bitstream/handle/1884/24694/D\%20\%20IMAGUIRE\%20JUNIOR,\%20KEY.pdf;jsessionid=7D29295995BB18A32096B654963EFE28? sequence=1.

Acesso em 02.junho.2016.
} 
Podemos perceber que a influência do barroco português esteve presente em todas as Igrejas, apesar das modificações que alteraram as características originais, ainda ficaram predominante os ornamentos exteriores e sua composição simples e campeira, típica do estilo barroco no Brasil.

\section{REFERÊNCIAS}

BALHANA, Altiva P.; MACHADO, Brasil P.; WESTPHALEN, Cecília M. História do Paraná. Curitiba: Grafipar, 1969

IMAGUIRE Junior, Key. Arquitetura no Paraná; contribuição metodológica à história da arte. Curitiba: UFPR/Mestrado em História, 1982.

LEÃO, Ermelino Agostinho. Diccionario histórico e geográfico do Paraná. Curitiba: s.e, 1994

LITTLE, Stephen. Ismos: para entender a História da Arte. São Paulo: Globo, 2010.

LYRA, Cyro Correa. Guia dos bens tombados - Paraná, Rio de Janeiro, Expressão e Cultura, 1994.

POZENATO, Kenia. Introdução a História da Arte, Caxias do Sul, RS: Ed. Maneco, 2013.

SECRETARIA DE ESTADO DA CULTURA. Espirais do tempo: bens tombados do Paraná, Curitiba: $\quad$ SEEC, $2006 . \quad$ Disponível em:< http://www.patrimoniocultural.pr.gov.br/arquivos/File/BIBLIOGRAFIACPC/ESPIRAIS/prg.pdf >. Acesso em: 6.novembro.2014.

WACHOWICZ, R. História do Paraná, Curitiba: Editora UEPG, 2010.

\section{FONTES PRIMÁRIAS}

FREIBERGER, Stefanie. Elevações 01 e 02 da Igreja de São Sebastião do Porto de Cima, Morretes, 2005.

FREIBERGER, Stefanie. Elevações 03 e 04 da Igreja de São Sebastião do Porto de Cima, Morretes, 2005.

FURQUIM, Ana. Elevação Lateral direita e posterior da Igreja do Bom Jesus do Saivá, Antonina, 2014.

FURQUIM, Ana. Elevação Lateral frontal e esquerda da Igreja do Bom Jesus do Saivá, Antonina, 2014. 
SOLANO, Enio. Elevação Frontal e Fundos da Igreja de Nossa Senhora do Bom Sucesso, Guaratuba, S.D.

SOLANO, Enio. Elevação Lateral 1 da Igreja de Nossa Senhora do Bom Sucesso, Guaratuba, S.D.

SOLANO, Enio. Elevação Lateral 2 da Igreja de Nossa Senhora do Bom Sucesso, Guaratuba, S.D.

\section{RELIGION AND ART IN COASTAL PARANAENSE: A RELEITURA CHURCHES XVIII CENTURY BAROQUE}

\section{ABSTRACT}

The paper analyzes the campeira architecture from the Portuguese colonization and its influences in the construction of the historical center of villages founded in the eighteenth century, including the development of the city through the construction of churches and thus demonstrate the influence of Portuguese occupation in the use of Baroque architecture of the time. The buildings analyzed are the Church of Our Lady of the Pillar of 1714, the Church of Bom Jesus will come out of 1789, both of Antonina; the Church of Sao Sebastiao do Porto de Cima, 1779, Morretes; and the Church of Our Lady of Good Success, 1766, in Guaratuba.

KEYWORDS: Churches, Litoral Paranaense, Baroque pampas, Brazil Cologne. 


\section{ANEXO A}

Igreja do Bom Jesus do Saivá

Localização: Praça Carlos Cavalcanti.

Data da construção: Século XVIII.

Proprietário: Mitra Diocesana de Paranaguá

Tombamento estadual: Processo $n^{\circ}$ 25/70. Inscrição nº 25, Livro do Tombo Histórico.

Data: $15 / 09 / 1970$.
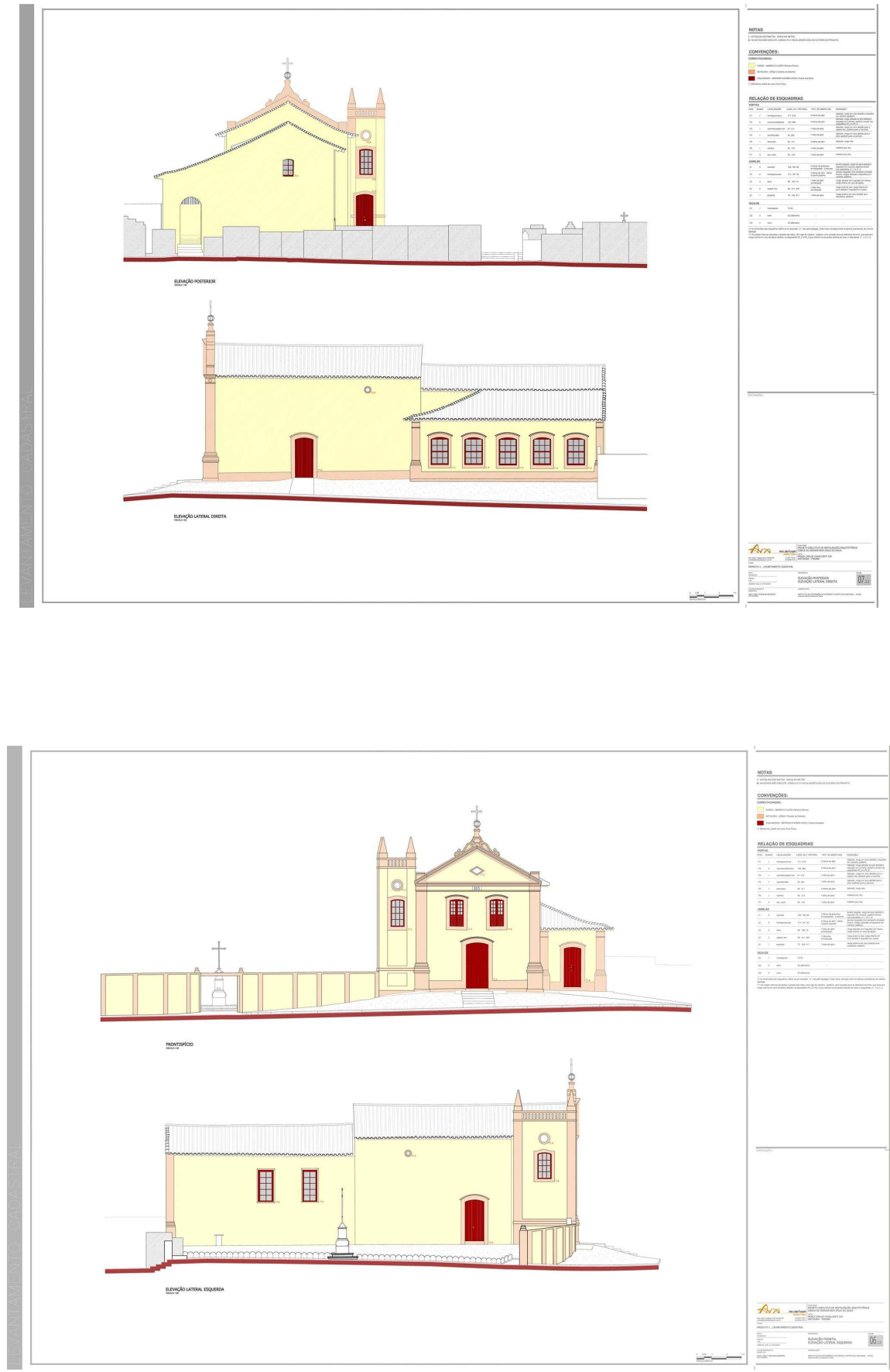
Igreja de Nossa Senhora do Pilar

\section{ANEXO B}

Localização: Praça Coronel Macedo.

Data da construção: início séc. XVIII.

Proprietário: Mitra Diocesana de Paranaguá.

Tombamento estadual: Processo $n^{\circ}$ 01/95. Inscrição nº 122. Livro do Tombo Histórico.

Data: 08/11/1999.
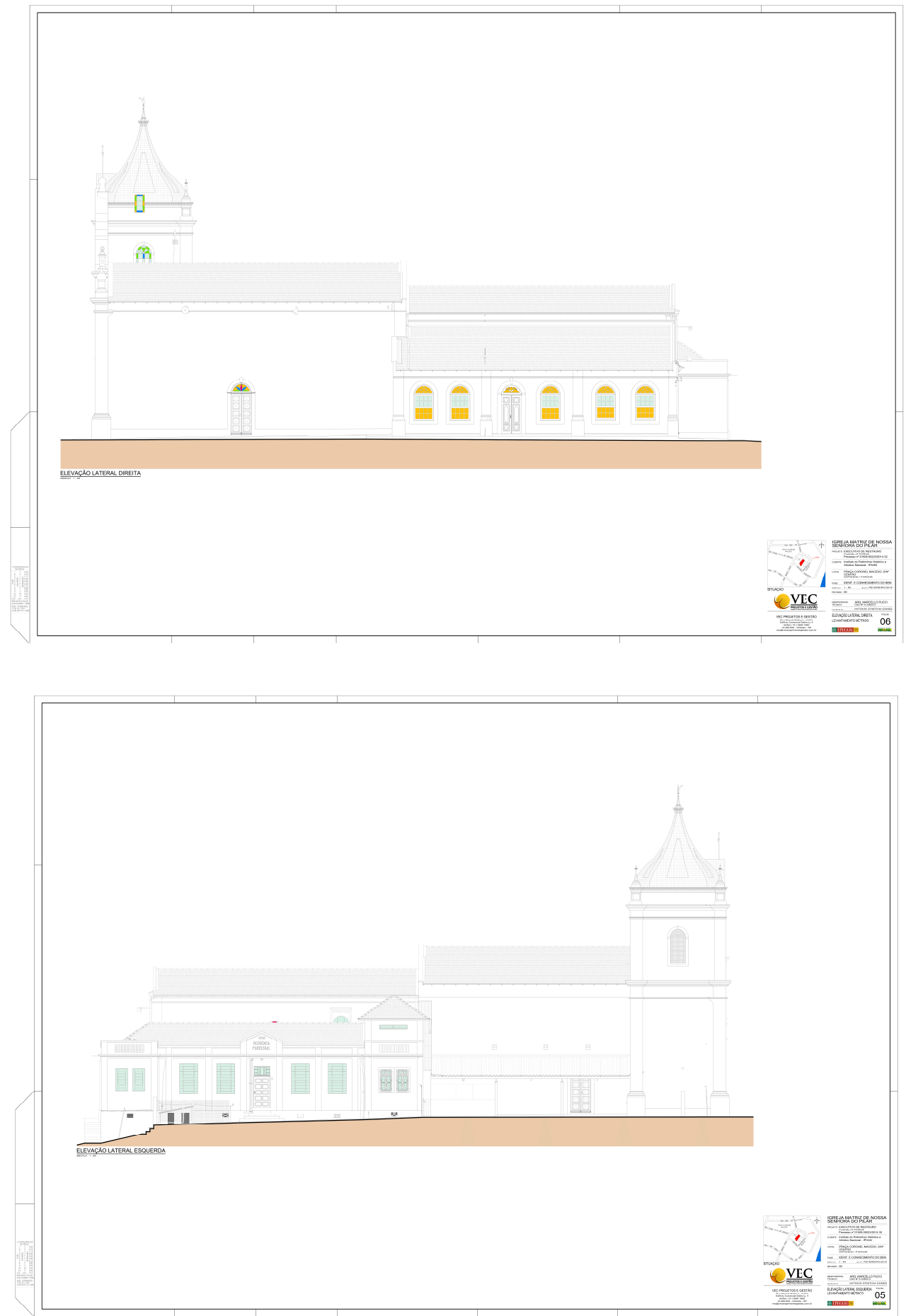


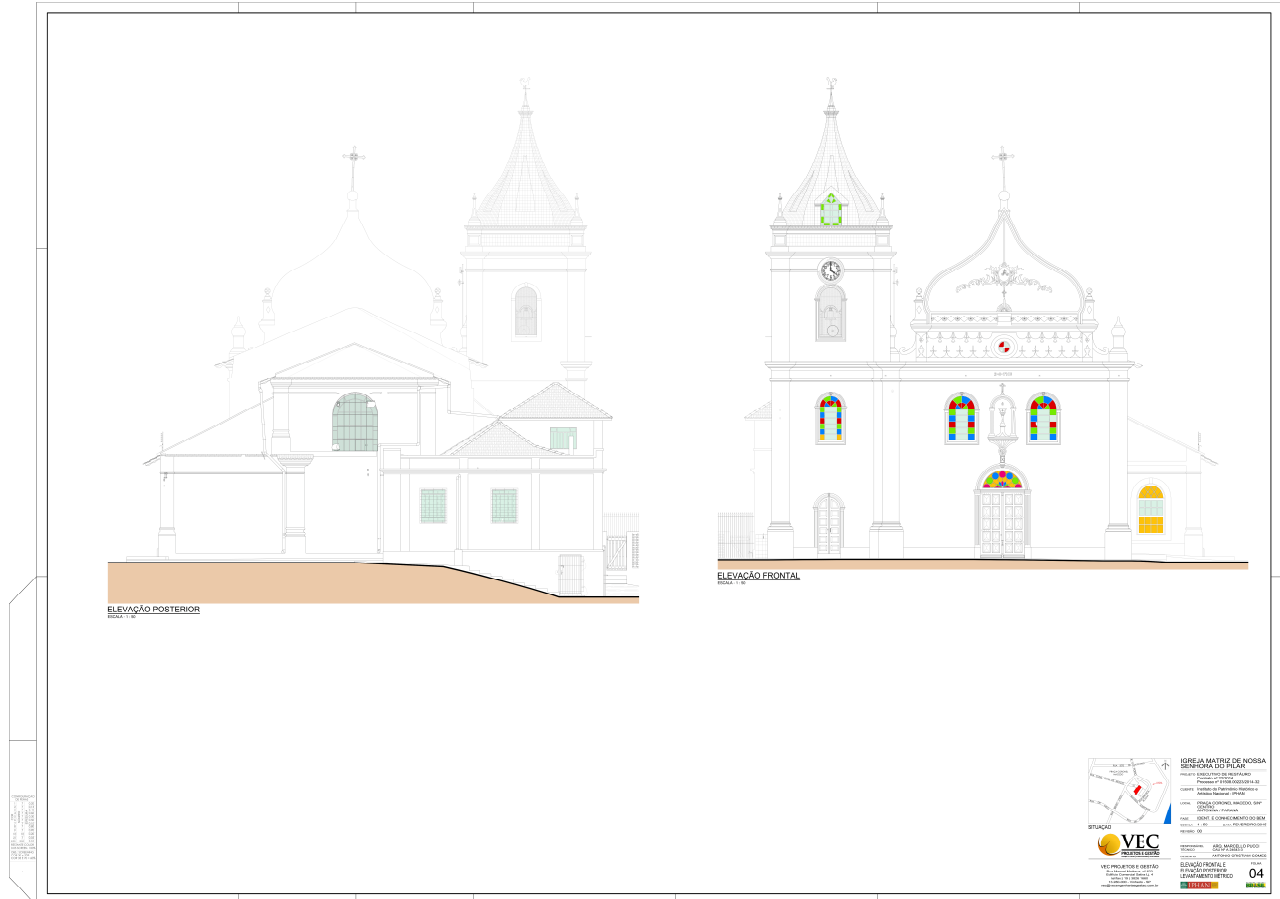




\section{ANEXO C}

Igreja Matriz de Nossa Senhora do Bom Sucesso

Data da construção: 1766-1771.

Proprietário: Mitra Diocesana de Paranaguá

Tombamento estadual: Processo $n^{\circ} 35 / 72$, Inscrição n³4, Livro do Tombo Histórico. Data: 29/02/1972.

Tombamento federal: Processo n ${ }^{\circ}$ 21-T, Inscrição n ${ }^{\circ}$. Livro das Belas Artes, fl 32.

Data: $14 / 4 / 1941$.
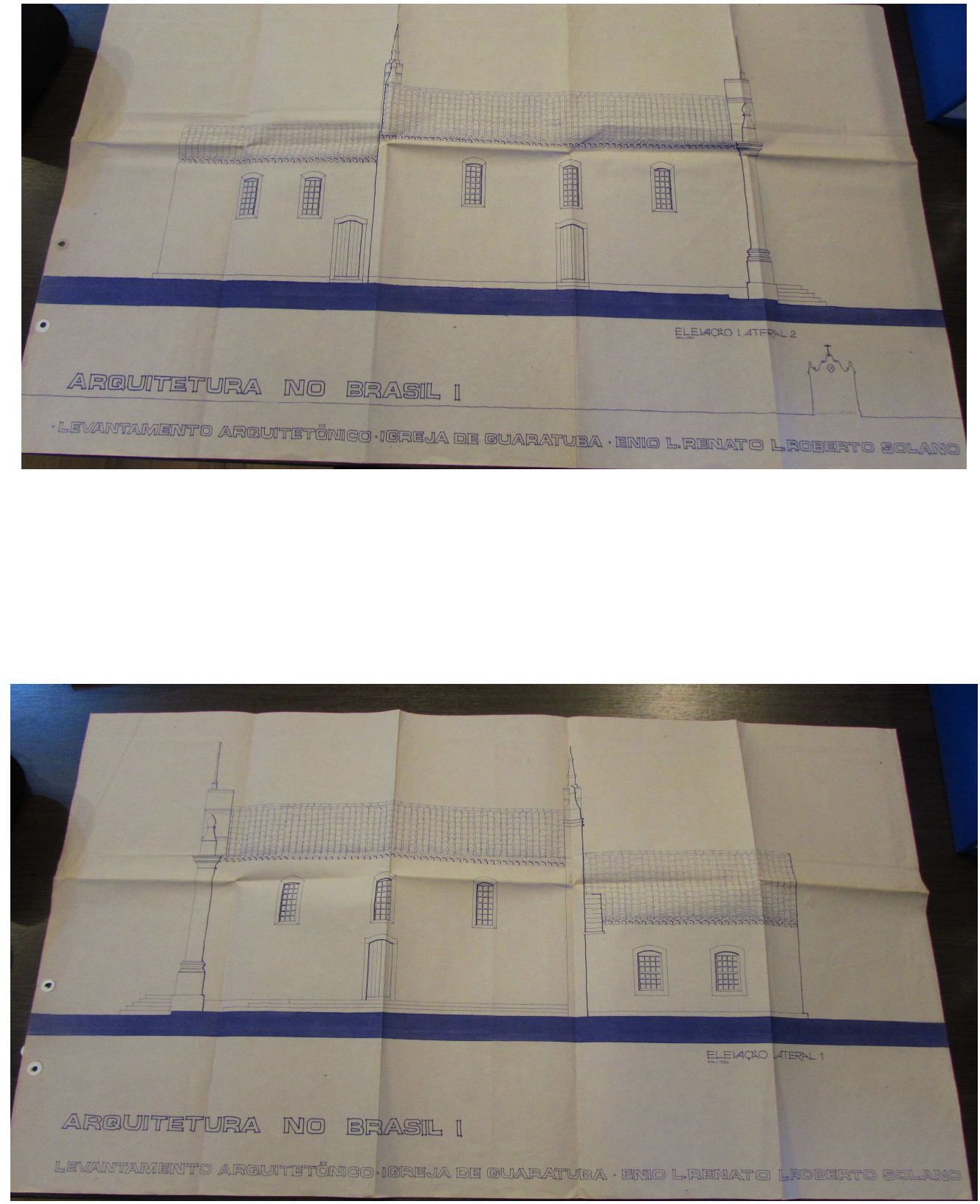


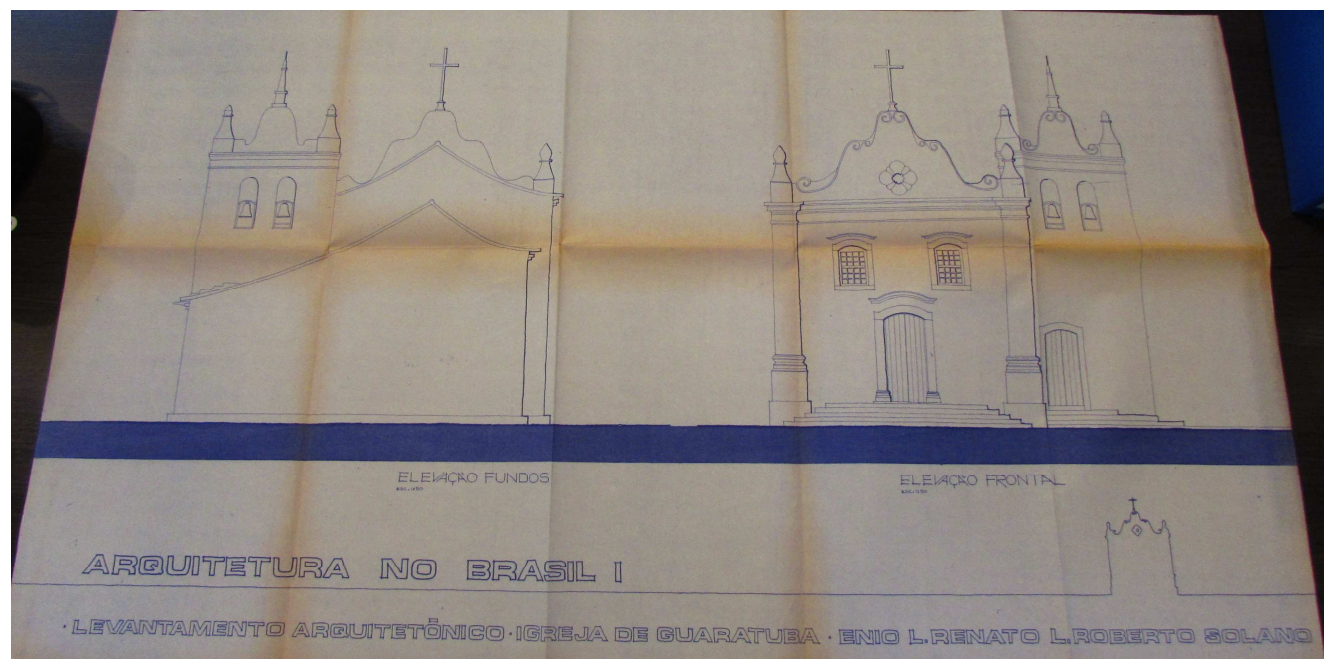


Igreja de São Sebastião do Porto de Cima

\section{ANEXO D}

Localização: Porto de Cima.

Data da construção: 1779.

Proprietário: Mitra Diocesana de Paranaguá

Tombamento estadual: Processo $n^{\circ}$ 222-03/63, inscrição: $n^{\circ}$ 03, Livro do Tombo Histórico. Data: 14/03/1963.

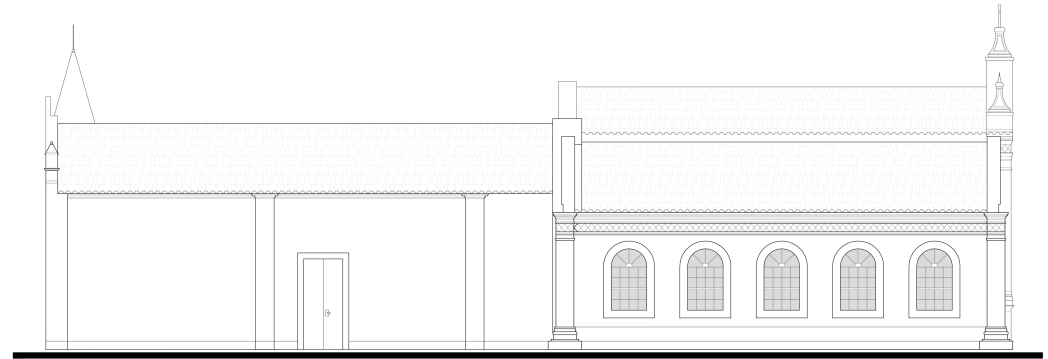

ELEVAÇÃO 01

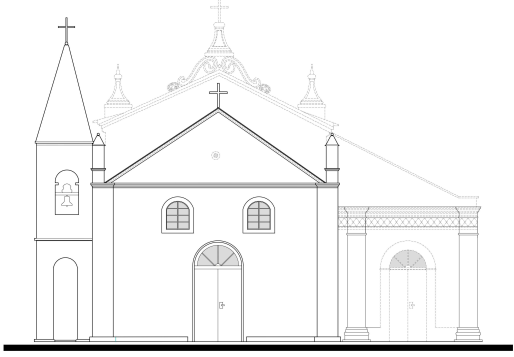

ELEVAÇÃO 02
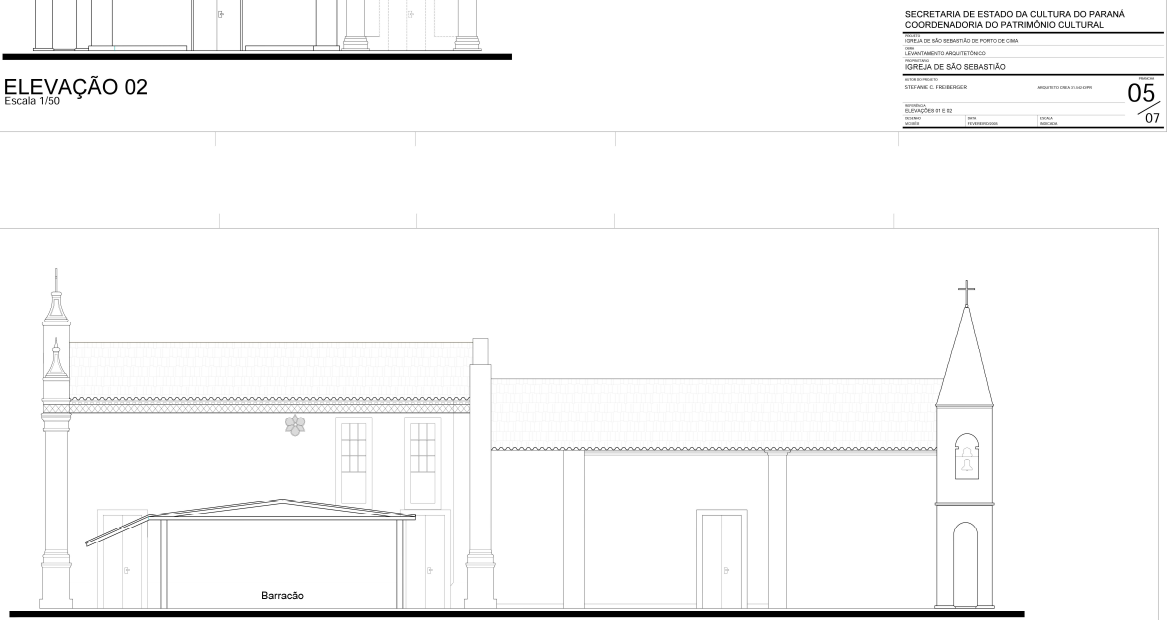

ELEVVAÇÃO 03

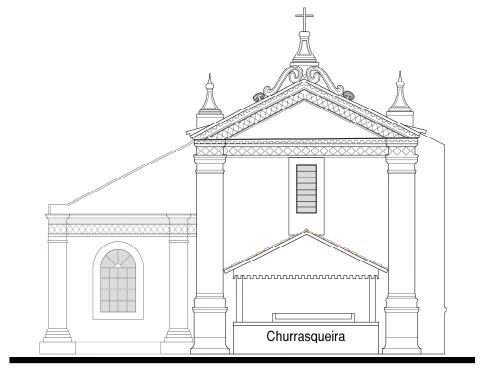

ELEVAÇÃO 04

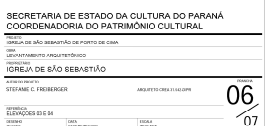

